\title{
Hunting for signs in the public space - the method of linguistic treasure hunts as a form of citizen science
}

\author{
Barbara Heinisch ${ }^{1}$ \\ Centre for Translation Studies, University of Vienna \\ Gymnasiumstraße 50, 1190 Vienna, Austria \\ E-mail: barbara.heinischeunivie.ac.at
}

Treasure hunts are games in which a group of people follows a series of clues to win a prize. Since the participants move in the public space, which is full of written texts, treasure hunts are also interesting to linguistic landscaping. Therefore, linguistic treasure hunts combine linguistic landscaping done by citizens with gamification to contribute to research on linguistic landscapes. The method of the linguistic treasure hunt aims at collecting and analysing language variation in written form in the public sphere. A group of people follows a series of clues through an urban space with the additional task to take, upload and tag pictures of signs and lettering in the public sphere. The group who solved the puzzles, uploaded the highest number of pictures and tagged them according to certain criteria wins a prize. The pilot study showed that the criteria, i.e. tags for the linguistic analysis of the pictures that were provided by the scholars may not only need further explanation but also a different prioritisation to find the right balance between data quantity and data quality.

\section{${ }^{1}$ Speaker}




\section{Linguistic landscaping through treasure hunts}

Treasure hunts are games in which a group of people can win a prize by following a series of clues that have been placed in order to direct them to a certain location. To get from one clue to another, the participants move in the public space. This space is particularly interesting for research on linguistic landscapes. A linguistic landscape includes billboard advertisements, shop signs, street names, road signs and stickers on lampposts. It is defined as "the visibility and salience of languages on public and commercial signs in a given territory or region" [1], thus serving different functions, such as being a marker of the relative status of linguistic communities in a region [1].

\subsection{Exploring linguistic landscapes with citizen science}

The citizen linguistics project "On everyone's mind and lips - German in Austria" (IamDiÖ) addresses the use and perception of and the attitude towards the German language in Austria. Therefore, one of its aims is to encourage citizens to search for and (preliminary) analyse written forms of language variation in the public space, thus contributing to the Lingscape project [2]. Lingscape combines linguistic landscaping and citizen science. Since it aims at the documentation and analysis of linguistic landscapes to study social semiotics, an app for uploading, georeferencing and tagging pictures of signs and lettering in the public space was developed [3]. This app was also used for the IamDiÖ linguistic treasure hunts, which combine treasure hunts with linguistic landscaping done by citizens [4]. This method is explained in the following.

\subsection{Linguistic treasure hunts}

Linguistic treasure hunts as a method in citizen science are a special form of treasure hunt tailored to the citizen humanities. The participants form groups and have to follow a series of clues placed in the public sphere to get to an aim. Additionally, they have to make as many photos as possible from written information in the public sphere between the locations of the clues. The photos must be uploaded to the Lingscape app and annotated, i.e. additional information on the picture must be provided, e.g. geographical location, language(s) found on the picture, the language variety, context, function or medium. The groups get points for the number of pictures uploaded and for the tags according to a weighting system (Table 1).

When uploading and tagging the pictures during a treasure hunt, it is a prerequisite that the participants use their group's hashtag so that the pictures can be assigned to the correct group. Then each group can score points according to the number of uploaded pictures (plus extra points for the group with the most pictures), the number of languages (more points for 'uncommon' languages in the region), the number of language varieties and the number of media and functions tagged. In addition, groups should take pictures of the clues which are provided as QR codes on paper at the different locations (Table 1).

The first treasure hunts which were launched in the course of the project served as pilot studies. The results showed that the categories for the analysis, i.e. the tags for the pictures, which were specified by the academics in advance, should have been adapted to the general language 
use and be described in more detail. Moreover, a discrepancy between data quality and data quantity could be observed.

\section{Discussion}

Linguistic treasure hunts are a form of citizen science that combine linguistic landscaping with gamification.

The advantages of this method are that large amounts of data can be gathered in a short period of time. The participants may also already make an initial analysis of the data they have gathered during the linguistic treasure hunts in the form of annotations with a tagging system. This vast collection of pictures from written signs in the public sphere helps enrich the data base for linguistic landscape research.

The drawbacks of this method are related to the gamification aspect itself. A treasure hunt bears a strong extrinsic motivation since participants can win a prize. The resulting competition may defer from the actual task of linguistic landscaping, i.e. participants may rather focus on solving the puzzles and being the first at the final location and not on taking and annotating pictures of the linguistic landscape. In the pilot treasure hunts, the quality of the initial analysis, i.e. annotation, as well as the accuracy of the geolocation of the uploaded pictures varied.

This may be caused by the gamification aspect and the competition and/or the annotation and point allocation systems. On the one hand, the discrepancy between data quantity and data quality in linguistic treasure hunts may be tackled by changing the criteria for winning, i.e. the point allocation system and introducing a quality control system. Currently, participants get points for the number of pictures uploaded and tagged according to certain criteria. By prioritising certain criteria (according to the scholar's research priorities), i.e. another weighting of the points, and introducing a quality control mechanism, the quality of the tags may increase.

On the other hand, a further specification and detailed description of the annotation system and a more comprehensive introduction to the annotation (tagging) system in advance may also increase the data quality. Moreover, since another strand of the IamDiÖ project addresses the cocreation of a citizen linguistics project, it would be interesting to test whether the development of the categories for annotation, i.e. the tags, together with the participants, may lead to different results.

An aspect that can be derived from linguistic treasure hunts and is relevant for research itself are the elements in a linguistic landscape that draw the participants' attention. This allows for research on the perception and salient features of signs in the public space.

Another form of a linguistic treasure hunt, and thus another way of implementing linguistic landscaping using citizen science is a LinguaBlitz. During a LinguaBlitz, which is derived from the concept of the BioBlitz [5], (a large number of) scholars and participants record a vast amount of linguistic landscape data comprehensively within a set region in a certain period of time. In comparison to linguistic treasure hunts, which mainly rely on the participant's attention and not on predefined routes, a LinguaBlitz would allow to cover a large area more comprehensively and systematically, thus being more aimed at creating an inventory than making a snapshot of a linguistic landscape. 
To sum up, gamification in citizen humanities projects in the form of linguistic treasure hunts, which address research on linguistic landscapes, may help to increase the motivation of the participants and the amount of data gathered in a short period of time but may impede data quality. However, initial training, a co-created annotation system and quality control mechanisms may help increase data quality in linguistic treasure hunts. 


\section{PoS \\ PROCEEDINGS \\ OF SCIENCE}

Table 1: Linguistic treasure hunts: Overview of aspects analysed, the related research rationale, annotation (tagging) system and scoring (developed by the IamDiö team)

\begin{tabular}{|c|c|c|c|c|c|c|}
\hline Scores & $\begin{array}{c}\text { (Hash)- } \\
\text { Tag }\end{array}$ & $\begin{array}{c}\text { Aspect of } \\
\text { analysis }\end{array}$ & Example & $\begin{array}{l}\text { Tagging } \\
\text { (in the app) }\end{array}$ & Points & Research rationale \\
\hline $\begin{array}{l}\text { Number of } \\
\text { pictures }\end{array}$ & & Motif & & & $\begin{array}{l}2 \text { points for } 5 \text { pictures }+ \\
2 \text { extra points for the group with the most pictures } \\
\text { The same motif must not be uploaded more than once } \\
\text { per group. }\end{array}$ & $\begin{array}{l}\text { The more pictures, the more data are } \\
\text { gathered in a linguistic landscape. }\end{array}$ \\
\hline $\begin{array}{l}\text { Number of } \\
\text { languages }\end{array}$ & & Language & & $\begin{array}{l}\text { The language(s) can } \\
\text { be selected from a } \\
\text { dropdown menu in } \\
\text { the Lingscape app. }\end{array}$ & $\begin{array}{l}1 \text { point for the languages German and English each, } \\
2 \text { points for any additional language }+ \\
2 \text { extra points for the most other languages }\end{array}$ & $\begin{array}{l}\text { Gathering more diverse data, not only the } \\
\text { most frequent languages. }\end{array}$ \\
\hline $\begin{array}{l}\text { Picture of the } \\
\text { clues (QR codes } \\
\text { on paper at } \\
\text { different } \\
\text { locations) }\end{array}$ & & (Puzzle solved) & & & 1 point per clue & $\begin{array}{l}\text { Gamification aspect; more transparency } \\
\text { regarding the geolocation of the other } \\
\text { pictures taken. }\end{array}$ \\
\hline Georeferencing & & Location & & $\begin{array}{l}\text { The location can be } \\
\text { selected on a map in } \\
\text { the app or via } \\
\text { smartphone GPS }\end{array}$ & $\begin{array}{l}\text { No points because this is a compulsory feature in the } \\
\text { app when uploading pictures. }\end{array}$ & $\begin{array}{l}\text { To analyse a linguistic landscape, the exact } \\
\text { location of a sign, etc. is needed. }\end{array}$ \\
\hline \multirow[t]{2}{*}{$\begin{array}{l}\text { Distance } \\
\text { between pictures }\end{array}$} & & & & & $\begin{array}{l}2 \text { points for the longest distance between two } \\
\text { pictures }\end{array}$ & $\begin{array}{l}\text { Gathering data from a broader area (but hard } \\
\text { to evaluate). }\end{array}$ \\
\hline & $\#$ & Group name & Super group & \#Supergroup & $\begin{array}{l}\text { All points are assigned to the group name. } \\
\text { The groups must use their group names in order to be } \\
\text { assigned points. }\end{array}$ & Gamification aspect \\
\hline $\begin{array}{l}\text { Number of } \\
\text { language } \\
\text { varieties }\end{array}$ & $\&$ & $\begin{array}{l}\text { Language } \\
\text { variety }\end{array}$ & $\begin{array}{l}\text { Dialect/vernacular } \\
\text { (Bavarian, Viennese, } \\
\text { Tyrolian), youth } \\
\text { language }\end{array}$ & \&Viennese & $\begin{array}{l}2 \text { points per language variety }+ \\
2 \text { extra points for the most language varieties }\end{array}$ & $\begin{array}{l}\text { Gathering data of intralingual linguistic } \\
\text { diversity. }\end{array}$ \\
\hline Number of media & \# & Medium & $\begin{array}{l}\text { Graffiti, sticker, } \\
\text { street sign, } \\
\text { advertisement } \\
\text { poster, road sign, } \\
\text { shop sign, inscription }\end{array}$ & \#Graffiti & $\begin{array}{l}1 \text { point for } 2 \text { media tags, } \\
2 \text { points for any additional tag + } \\
2 \text { extra points for the most tags }\end{array}$ & Gathering data of different text types. \\
\hline $\begin{array}{l}\text { Number of } \\
\text { functions }\end{array}$ & \# & $\begin{array}{l}\text { Function (signs } \\
\text { that have been } \\
\text { added later) }\end{array}$ & $\begin{array}{l}\text { Comment, } \\
\text { translation, } \\
\text { additional } \\
\text { information }\end{array}$ & \#Comment & 1 point per tag & $\begin{array}{l}\text { Gathering data of language status, discourse } \\
\text { in the public space, etc. }\end{array}$ \\
\hline $\begin{array}{l}\text { Number of } \\
\text { scripts }\end{array}$ & $=$ & Script & $\begin{array}{l}\text { Greek, Cyrillic, } \\
\text { Arabic }\end{array}$ & $=$ Cyrillic & 1 extra point & Quality control for language identification. \\
\hline $\begin{array}{l}\text { Number of } \\
\text { contexts }\end{array}$ & $@$ & Context & $\begin{array}{l}\text { Train station, café, } \\
\text { park }\end{array}$ & $@$ Park & 1 extra point & Quality control for georeferencing. \\
\hline $\begin{array}{l}\text { Number of types } \\
\text { of motif }\end{array}$ & \# & Type of motif & $\begin{array}{l}\text { Menu in a } \\
\text { restaurant, } \\
\text { scribbling in public } \\
\text { toilet }\end{array}$ & \#Menu in a restaurant & 1 extra point & Quality control for medium and function. \\
\hline $\begin{array}{l}\text { Number of own } \\
\text { translations }\end{array}$ & $\epsilon$ & $\begin{array}{l}\text { Own } \\
\text { translation }\end{array}$ & & & 1 extra point & $\begin{array}{l}\text { Quality control for language and language } \\
\text { varieties. }\end{array}$ \\
\hline
\end{tabular}




\section{References}

[1] R. Landry and R. Y. Bourhis, Linguistic Landscape and Ethnolinguistic Vitality, Journal of Language and Social Psychology 16(1997) 23, doi: 10.1177/0261927X970161002.

[2] C. Purschke, Crowdsourcing the linguistic landscape of a multilingual country. Introducing Lingscape in Luxembourg(2017), doi: 10.13092/lo.85.4086.

[3] C. Purschke, (T)Apping the linguistic landscape, Linguistic Landscape 3(2018) 246, doi: 10.1075/11.17023.pur.

[4] M. E.-H. Seltmann and B. Heinisch, How to speak German in Austria. Collaboration between two linguistic citizen science projects - "On everyone's mind and lips - German in Austria" and "Lingscape" found each other. In Austrian Citizen Science Conference 2018. University of Salzburg, Austria. February 01-03, 2018, pp. 82-85.

[5] G. M. Baker, N. Duncan, T. Gostomski, M. A. Horner and D. Manski, The bioblitz: Good science, good outreach, good fun, Park Science 31(2014) 39. 